\title{
A meta-analysis and meta-regression of the effects of vitamin E supplementation on serum enrichment, udder health, milk yield, and reproductive performance of transition cows
}

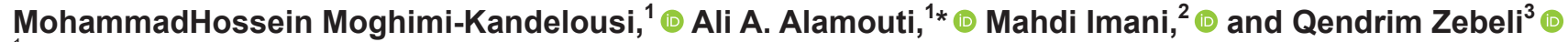 \\ ${ }^{1}$ Department of Animal and Poultry Sciences, College of Aburaihan, University of Tehran, Tehran, Iran 3391653755 \\ ${ }^{2}$ Department of Animal Sciences, University College of Agriculture and Natural Resources, University of Tehran, Karaj, Iran 3158777871 \\ ${ }^{3}$ Department for Farm Animals and Veterinary Public Health, Institute of Animal Nutrition and Functional Plant Compounds, Vetmeduni Vienna, \\ Austria 1210
}

\begin{abstract}
Vitamin $\mathrm{E}$ is an essential nutrient for cows, but the effect of vitamin E supplementation is often controversially discussed in the published literature. The main goal of this meta-analysis was to evaluate the effects of vitamin E supplementation on its serum and colostrum enrichment, milk yield (MY), and somatic cell counts (SCC), as well as on various reproductive variables of transition cows, by considering a large set of variables that might influence the responses to vitamin E supplementation. After a broad search in journals and databases with keywords related to transition cows supplemented with vitamin $\mathrm{E}$ and appropriate filtering of the results, 36 papers including 53 trials were selected, and their data were extracted into a database. A meta-analysis was conducted on the extracted data. The analysis showed enrichment of serum vitamin E both at parturition (effect size: 2.423) and postpartum (effect size: 0.473 ), but no effects of vitamin E supplementation on IgG concentration in colostrum (effect size: -0.05 ) were found. There was a tendency for supplemented cows to produce more milk (effect size: 1.29) during the first month of lactation. Because of large heterogeneity, a meta-regression was performed but none of the presumed influencing factors was identified as a potential variable affecting MY. Milk SCC, as an indicator of udder health, was unaffected by vitamin E supplementation. Vitamin E supplementation tended to decrease the calving to first estrus period (CFP), whereby supplementing Se and taking parity into account in the analysis significantly lowered the CFP. Cows receiving additional vitamin $\mathrm{E}$ had, on average, $6.1 \%$ fewer cases
\end{abstract}

Received September 7, 2019 .

Accepted March 3, 2020.

*Corresponding author: a.alamouti@ut.ac.ir of retained placenta, whereby Se supplementation and breed were key factors improving the effect of vitamin $\mathrm{E}$ to reduce retained placenta. In this regard, breeds other than Holstein responded better and these cows showed a lower incidence of retained placenta. The supplemented cows showed fewer days open (effect size: -0.31 ), and this improvement was affected linearly by increasing the dosage administered. Also, cows showed fewer services per conception with increasing dosage of vitamin E. In conclusion, this analysis showed that supplementing vitamin E did not affect SCC or colostrum quality but improved reproductive performance of transition cows, an effect consistent with increased levels of serum vitamin $\mathrm{E}$ and, for some variables, being modulated by Se supplementation.

Key words: dose response, retained fetal membranes, transition cow, vitamin $\mathrm{E}$

\section{INTRODUCTION}

During the transition period (i.e., 3 wk before and after calving), dairy cows experience severe energy and nutrient deficits accompanied by peripartal stress, excessive mobilization of body tissues, cellular damage, and inflammation. These events lead to disequilibrium in oxidant or antioxidant capacity of the body, resulting in oxidative stress, associated with an altered immune function (Kehrli and Shuster, 1994), which increases the risk of periparturient diseases (Pontes et al., 2015; Schäfers et al., 2018). Vitamin E has essential antioxidant functions: trapping peroxyl radicals (Baldi, 2005), minimizing the formation of secondary radicals, reducing the oxidative stress, and helping to stabilize the cell membranes (Bass, 1999; Morgante et al., 1999; Torsein et al., 2018).

Vitamin E has long been supplemented in the diets of dairy cows with levels that vary between 18 and $73 \mathrm{IU}$ of all-rac- $\alpha$-tocopherol $/ \mathrm{kg}$ of DMI for dry and lactating cows, respectively (NRC, 2001). Politis (2012) 
recommended daily doses of 1,000 to $3,000 \mathrm{IU}$ and 500 to 1,000 IU of vitamin $\mathrm{E}$ for dry and lactating cows, respectively, which is higher than NRC (2001) recommendations (i.e., 1,200 IU/head and $545 \mathrm{IU} /$ head per day for close-up and fresh cows, respectively). Baldi et al. (2000) found that increasing oral vitamin E supplementation at 1,000 IU/cow per day reduced SCC in the milk by approximately $30 \%$. In contrast, other studies showed no effects of vitamin $\mathrm{E}$ supplementation on SCC levels (Bouwstra et al., 2010). Nevertheless, 2 experiments conducted by Chandra et al. (2013) revealed that simultaneous supplementation of vitamin $\mathrm{E}$ with zinc or with $\beta$-carotene improved metabolic status or immune function, respectively, of transition cows. Thus, the controversial outcomes of previous studies might be due to different sources of variation and interactions, which cannot be fully controlled in single trials. Several other factors may affect vitamin E availability and its efficiency in animals, including source of the vitamin $\mathrm{E}$ active substance, other nutrients in feeds (Campbell and Miller, 1998; Chandra et al., 2014), timing, inclusion of Se (Aréchiga et al., 1994), variation in vitamin E content of the basal ration (Lindqvist et al., 2011), and method of administration (e.g., ruminal pellets or premixes in diet, or even i.v., s.c., and i.m. injection; Aréchiga et al., 1994; Bayril et al., 2015), applied over different time spans and frequencies with cows fed different diets and levels of production.

Meta-analysis has become a useful tool in animal science research, especially to summarize effects of treatment across studies and to investigate factors that help explain potential heterogeneity of animal responses (St-Pierre, 2001). Bourne et al. (2007) investigated the effects of vitamin E supplementation on the incidence of retained fetal membranes (RFM) in dairy cows using meta-analysis. However, these authors did not include or weight the effects of vitamin E supplementation by meta-regression models for various dietary and animal effects (e.g., level and effective isomer of vitamin $\mathrm{E}$ administered, added Se, method and duration of supplementation, before or after calving, parity, and breed of cows).

We hypothesize that some of the reported effects in the literature are due to inconsistencies in experimental conditions and that the true effects of vitamin $\mathrm{E}$ administration need to be elicited by aggregating all probable causes of uncertainty and results to confirm whether vitamin E supplementation during this period is beneficial. Therefore, the objective of this study was to conduct a comprehensive meta-analysis of the effects of vitamin E supplementation during the transition period on productive and reproductive traits and serum levels of vitamin $\mathrm{E}$.

\section{MATERIALS AND METHODS}

\section{Data Search}

Throughout this paper, the terms "vitamin E" and " $\alpha$-tocopherol" are used interchangeably. A broad search was performed using relevant keywords such as "late gestation," "prepartum," "parturition," "transition," "dairy," "cattle," "beef," "cow," "vitamin E," "tocopherol," "reproduction," "reproductive," and "performance"; journal papers, conference papers, and dissertations published between 1979 and August 2018 were included in this search. A total number of 528 publications (i.e., journal papers, abstracts, theses, and dissertations; Figure 1) were initially extracted from various databases, using Science Direct (87), Scopus (259), Web of Science (62), and Google Scholar (120) search engines. A closer filtration removed repeated publications (122 articles), those not related to cattle or transition period [(i.e., studies about goats (55 papers), sheep (94 papers), buffalo (51 papers)], and studies in which the transition period was incompletely examined (126), leaving about 80 papers. Authors with inaccessible full texts were contacted; the abstracts of papers without available full texts were excluded. The following inclusion criteria were applied: (1) a control group with no supplementation of vitamin $\mathrm{E}$ being used in the research, (2) cows were randomly allocated to treatments, (3) parameters of variation and significance (i.e., n, standard deviation, and $P$-value) were reported. Eventually, 36 papers met the criteria and their data were extracted to build a database. For papers including more than one vitamin E supplementation level, comparison of control versus each treatment mean (i.e., vitamin E level) was considered as an individual trial.

A summary of the papers used for the various metaanalyses is provided in Supplemental Table S1 (https: //doi.org/10.3168/jds.2019-17556). There were 36 papers containing 53 trials in which the effects of vitamin $\mathrm{E}$ administration on performance [i.e., daily milk yield (MY), SCC, and colostrum IgG concentration], reproduction [i.e., calving to first estrus period (CFP), days open (DO), number of services per conception (SPC) and percentage of cows with RFM], and blood concentration of vitamin $\mathrm{E}$ (before, at, and after calving) were reported. A total of 24 papers co-supplemented vitamin E with elemental Se compounds (e.g., as selenite salt and pentahydrate disodium). Among all papers, $45 \%$ supplemented vitamin $\mathrm{E}$ as part of a premix in basal ration or as intraruminal pellets, both of which were classified as an oral method of supplementation in the analysis. In the rest of papers, i.m. or s.c. injections of vitamin $\mathrm{E}$ were investigated. Overall, 22 studies were 


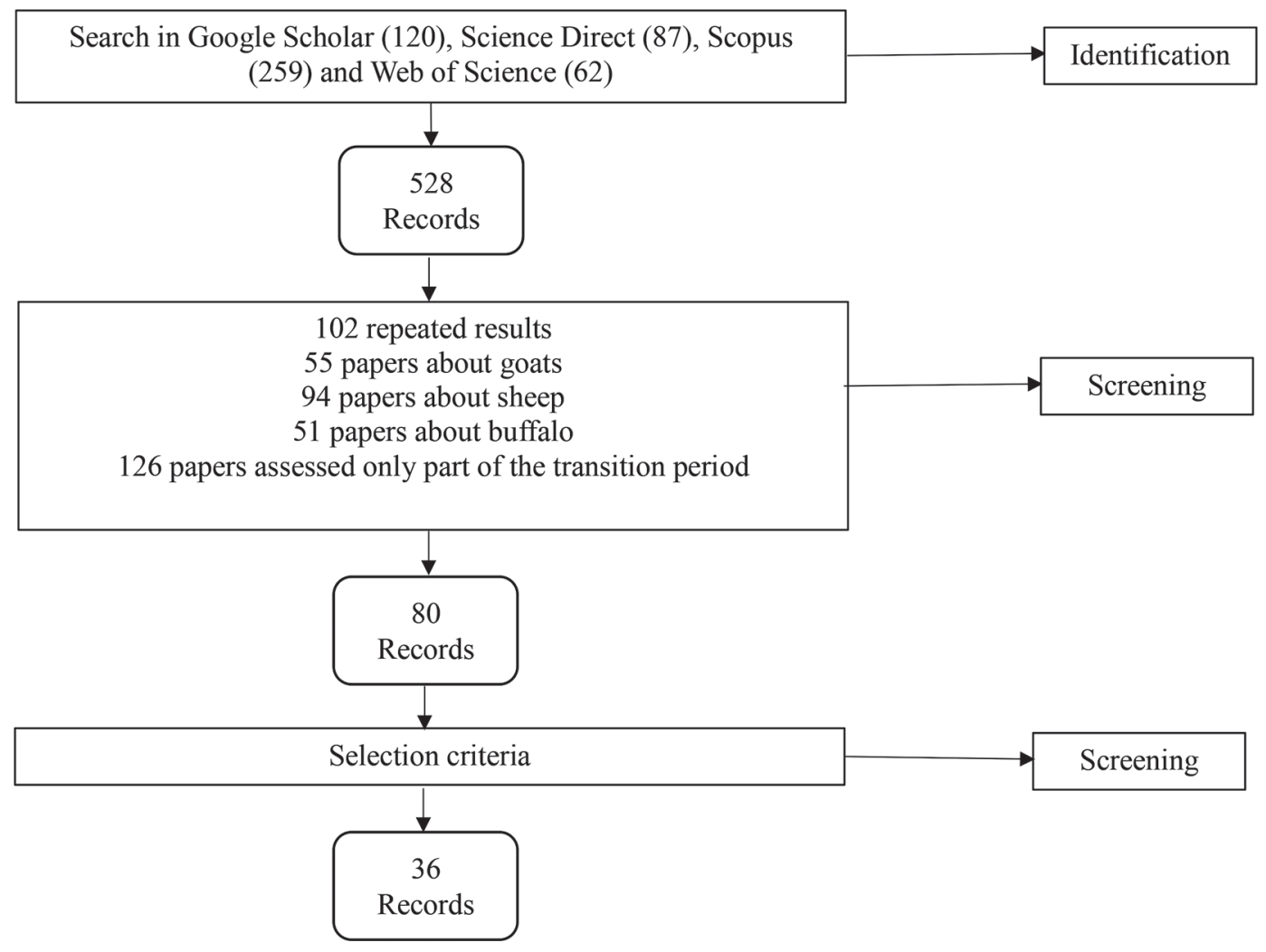

Figure 1. Flow diagram of identification and screening process in the literature search.

conducted on Holstein cows, whereas the other 14 studies used other breeds. In 10 studies, primiparous and multiparous cows were studied, whereas in the remainder, treatments were applied only in multiparous cows.

Variables originally considered as potentially influencing the outcomes of meta-analysis were Se supplementation, season of calving, chemical form of vitamin $\mathrm{E}$, production system (grazing or intensive), forage source (e.g., hay, grass, silage, haylage), forageto-concentrate ratio, dietary energy, $\mathrm{CP}$ and $\mathrm{NDF}$ concentrations, previous average $305-\mathrm{d}$ in milk, method of vitamin E administration, number of days treated pre- and postpartum, parity, and breed of cows. However, many of these factors were not reported in the papers in the minimum numbers required to include in the meta-analysis. Hence, the variables used in the final meta-analysis were Se supplementation, method of vitamin $\mathrm{E}$ administration, number of days treated pre- and postpartum, parity, and breed of cows.

\section{Statistical Analyses}

A funnel plot approach was used to assess publication bias. A meta-analysis was conducted on the extracted outcomes using R i386 3.5.0 (Metafor package, 2014; https://www.R-project.org/). The Metafor package provides functions for fitting various models. The various meta-analytic models can be fitted with the rma() function in R. A random effects model was conducted for each treatment to estimate the effect size, $95 \%$ confidence intervals, and statistical significance of effect size (Nasrollahi et al., 2015).

Under a random effects model, the goal is not to estimate one true effect, but to estimate the mean of a distribution of effects. Because each study provides information about a different effect size, we aimed to ensure all these effect sizes are represented in the summary estimate. By doing so, this approach does not discount a small study by giving it a very small weight in fixed effects analysis. The estimate provided by such a study may be less precise than that of larger studies, but it can yield information about an effect that no other study has estimated. Similarly, this approach ensures we do not give too much weight to a very large study in the fixed effects analysis (Borenstein et al., 2009). Hence, the effect size was computed by standardized mean difference (SMD) for each variable as follows (Nasrollahi et al., 2015): 


$$
S M D=\frac{\mu_{1}-\mu_{2}}{\sqrt{\sigma_{1}^{2}+\sigma_{2}^{2}}}
$$

where $\mu_{1}$ and $\mu_{2}$ are the means of treatment levels and control group, respectively; and $\sigma_{1}^{2}$ and $\sigma_{2}^{2}$ are the variances of treatment levels and control group, respectively. The model was

$$
Y_{i}=\theta_{i}+\varepsilon_{i}=\mu+\zeta_{i}+\varepsilon_{i}
$$

where $Y_{i}$ is determined by the true effect $\theta_{i}$ plus the within-study error $\varepsilon_{i}$. In turn, $\theta_{i}$ is determined by the mean of all true effects, $\mu$, and the between-study error $\zeta_{i}$.

The $I^{2}$ statistic describes the percentage of total variation across studies due to heterogeneity rather than chance; $I^{2}$ was calculated as follows:

$$
\begin{gathered}
I^{2}=\left(\frac{Q-(k-1)}{Q}\right) \times 100 ; \\
\text { where } Q=\sum_{i=1}^{k} W_{i} Y_{i}^{2}-\frac{\left(\sum_{i=1}^{k} W_{i} Y_{i}\right)^{2}}{\sum_{i=1}^{k} W_{i}} \text { and } \\
W_{i}=\frac{1}{\left(\sigma^{2} / n\right)},
\end{gathered}
$$

where $Q$ reflects the total variance and $k$ is the number of studies. Uncertainty intervals for $I^{2}$ (dependent on $Q$ and $k$ ) were calculated. Publication bias was investigated both graphically with funnel plots and statistically using tests from Begg and Mazumdar (1994) and Egger et al. (1997). In the case of significant publication bias, the number of studies needed to reverse the reported findings (fail-safe $n$ ) was calculated based on Rosenthal's method (Rosenthal, 1979).

A meta-regression was conducted when $I^{2}$ was significant $(P<0.05)$. The model was defined as follows:

$$
Y_{i}=\beta_{0}+\beta_{1} x_{1 i}+\varepsilon
$$

where $Y_{i}$ is the effect size in study $i$ and $\beta_{0}$ (intercept) is the estimated overall effect size. The variables $\beta_{1} x_{1 i}$ specify different characteristics of the study, and $\varepsilon$ specifies the between-study variation.

\section{Dose-Response Meta-Analysis}

Dose-response meta-analysis was performed by "dosresmeta" package in R (https://www.r-project.org/) to describe the main aspects of methodology (e.g., covariances of correlated outcomes, pooling of study-specific trends, flexible modeling of the exposure; Crippa and Orsini, 2016). It consists of a collection of functions to estimate dose-response relations from summarized dose-response data for both continuous and binary outcomes (Crippa and Orsini, 2016).

\section{RESULTS}

\section{Effects of Supplementation on Milk, Colostrum, and Blood Variables}

Six papers (12 independent trials) were used in metaanalysis of MY, in which 8 trials reported positive effects of the supplementation (Supplemental Table S1; https://doi.org/10.3168/jds.2019-17556). Supplemental Figure S1 (https://doi.org/10.3168/jds.2019-17556) summarizes studies that reported MY of cows after calving. The x-axis of Supplemental Figure S1 shows the SMD of trials in which MY was assessed after a period of vitamin E supplementation to periparturient cows. The dotted vertical line represents an effect size of zero (control group). The size of each square above the horizontal line shows the weight of the corresponding trial in overall effect size (i.e., the diamond below the vertical line). Upper and lower limits of the $95 \%$ CI of each trial and overall effect size are illustrated by error bars and length of diamond, respectively. The analysis shown in Table 1 indicated a mean difference of $1.06 \mathrm{~kg}$ of milk/d and an effect size of 1.29 (95\% CI: $-0.06,2.63 ; P=0.06)$. However, the heterogeneity of MY response was very large for this variable (918.67, $P<0.001)$. Although significant linear and quadratic responses to dosage of vitamin $\mathrm{E}$ administration were observed on MY $(P=0.05$ and $P=0.003$, respectively), meta-regression showed that breed, Se supplementation, number of days treated prepartum, parity, and method of administration did not alter the effect of vitamin $\mathrm{E}$ administration on $\mathrm{MY}$ in the first month of lactation.

\section{Effect on SCC in Milk}

Only a limited number of studies reported milk components other than SCC; therefore, they were not included in the meta-analysis. Overall results of the meta-analysis showed an effect size of 0.25 ( $P=$ 0.70, Supplemental Table S1) implying nonsignificant 


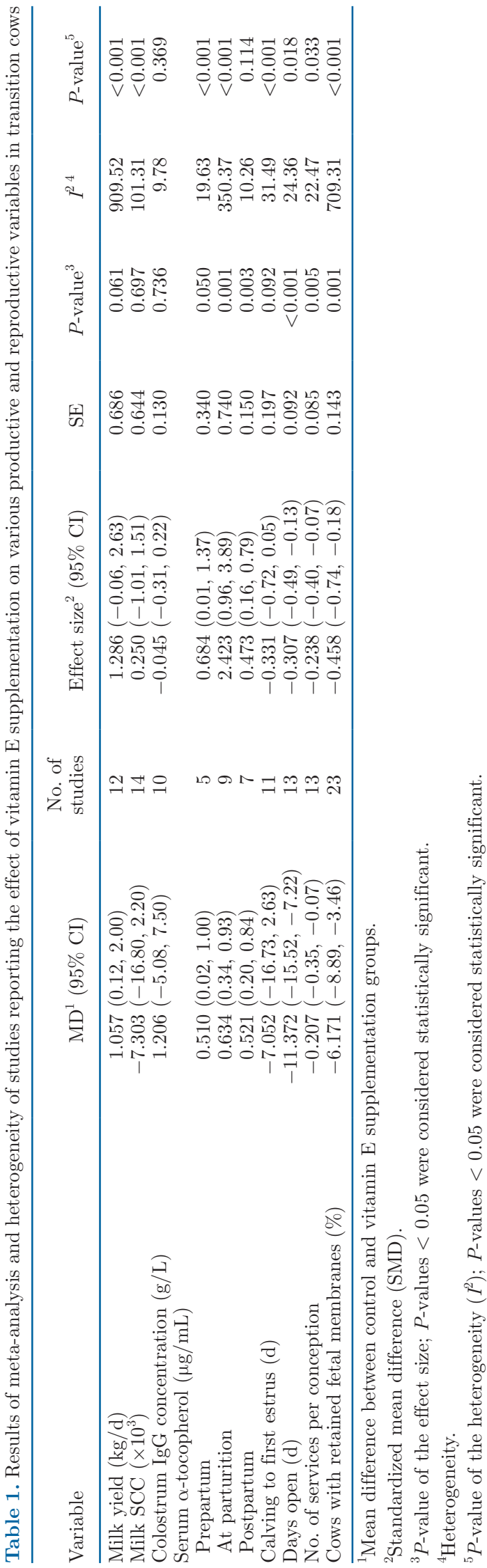

changes in milk SCC with vitamin E administration, which is depicted as a forest plot in Supplemental Figure S2 (https://doi.org/10.3168/jds.2019-17556). The supplementation dosage had no effect on SCC $(P=$ 0.42 and 0.43 for linear and quadratic, respectively). Heterogeneity between studies was highly significant $(P<0.001)$. However, none of the factors included in analysis was able to improve the accuracy of the metaregression model (Table 2).

\section{Effect on IgG Concentration in Colostrum}

The meta-analysis findings for the effect of vitamin $\mathrm{E}$ on $\mathrm{IgG}$ concentration in colostrum are reported in Table 1. A meta-analysis of 10 trials showed an effect size of $-0.045(P=0.74)$ for IgG concentration in colostrum, indicating no effect of vitamin E supplementation on colostrum IgG status. Also, heterogeneity of studies was not significant $(P=0.37$, Table 1$)$ and dosage of supplementation did not affect colostrum IgG concentration (dose-response $P$-values for linear and quadratic effects were 0.56 and 0.48 , respectively).

\section{Serum a-Tocopherol Concentration Around Parturition}

Serum $\alpha$-tocopherol concentrations prepartum $(P$ $=0.048)$, postpartum $(P=0.003)$, and on the day of calving $(P=0.001)$ were increased by vitamin $\mathrm{E}$ supplementation (Supplemental Figure S3; https://doi .org/10.3168/jds.2019-17556). Results demonstrated heterogeneity between studies on the effect of vitamin $\mathrm{E}$ on and after the day of calving $(P<0.001)$. In this regard, breed $(P=0.04)$ influenced serum $\alpha$-tocopherol concentration at parturition. Moreover, postpartum serum $\alpha$-tocopherol was higher for multiparous cows than for primiparous cows $(P=0.01)$. Conversely, added Se decreased postpartum serum $\alpha$-tocopherol $(P=0.01)$. Serum $\alpha$-tocopherol concentration on the day of calving was linearly increased $(P<0.001)$ by incremental levels of vitamin $\mathrm{E}$ administration but this response was not observed linearly or quadratically before and after parturition $(P>0.05)$.

\section{Effect on Reproductive Performance}

The mean difference of vitamin $\mathrm{E}$ administration on $\mathrm{CFP}$ was $-7.05 \mathrm{~d}$, demonstrating a trend for improvement in this variable $(P=0.09$, Table 1$)$. Interestingly, meta-regression showed that added Se interacted negatively with vitamin $\mathrm{E}(P=0.03)$. Also, multiparous cows receiving vitamin $\mathrm{E}$ had a shorter $\mathrm{CFP}$ than primiparous cows $(P=0.04)$. Dosage of supplementation showed a linear reduction of $\mathrm{CFP}(P=0.03)$ and 
quadratically increased the effect of vitamin $\mathrm{E}$ on $\mathrm{CFP}$ $(P=0.02)$.

Results of 15 trials that reported DO indicated that vitamin $\mathrm{E}$ reduced DO of cows in most studies (Supplemental Figure S4; https://doi.org/10.3168/jds.2019 -17556). The mean difference was $-11.37 \mathrm{~d}(95 \% \mathrm{CI}$ : $-15.52,-7.22)$ with an effect size of $-0.31(P<0.001)$ for cows supplemented with vitamin $\mathrm{E}$ (Table 1). The meta-regression showed that number of days treated prepartum shortened DO $(P=0.002)$, whereas parity extended DO $(P=0.02)$ in vitamin E-treated cows (Table 2), explaining some of the variation associated with cows' response to vitamin $\mathrm{E}$ supplementation. Moreover, the dosage of vitamin E linearly decreased the DO of cows with a small regression coefficient of $-0.0003(P=0.004)$.

The outcome of the meta-analysis revealed a 0.21 unit reduction in SPC with an effect size of -0.24 ( $P$ $=0.005$; Supplemental Figure S5; https://doi.org/10 $.3168 /$ jds.2019-17556). The SPC responded linearly to the dosage of vitamin $\mathrm{E}(P=0.012)$, and number of days treated prepartum and added Se decreased the $\mathrm{SPC}$ in the meta-regression model $(P<0.005)$. Moreover, increasing levels of vitamin $\mathrm{E}$ supplementation linearly reduced SPC $(P=0.01)$.

Results showed a significant effect size of -0.46 for $\mathrm{RFM}$, meaning that vitamin $\mathrm{E}$ decreased the incidence of RFM by $6.17 \%$. Except in 4 studies, vitamin $\mathrm{E}$ reduced RFM (Supplemental Figure S6; https://doi .org/10.3168/jds.2019-17556). Meta-regression showed significant effects of Se supplementation and breed of cows in response to vitamin $\mathrm{E}(P=0.04$ and 0.03 , respectively). In this regard, other breeds were more responsive to vitamin E supplementation than Holstein and showed a lower incidence of RFM. Both linear and quadratic effects of dosage of vitamin $\mathrm{E}$ were significant in reducing $\operatorname{RFM}(P<0.001)$.

\section{DISCUSSION}

Vitamin E plays a vital role in neutralizing reactive oxygen species (Bass, 1999), the intercellular substances that dramatically increase around calving. At the cellular level, vitamin $\mathrm{E}$ ends a chain reaction by donating its phenolic hydrogen to lipid peroxyl radicals and converting them to less destructive $\alpha$-tocopheroxyl radicals (Baldi, 2005), and consequently maintaining membrane integrity (Aréchiga et al., 1994). Therefore, it is likely that the critical contribution of vitamin $\mathrm{E}$ in neutralization of reactive oxygen species would be enhanced by increasing its level of supplementation.

Although we originally aimed to evaluate the effects of several potential interacting variables that could modulate the effects of supplementation or dosage of

Table 2. Results of meta-regression and effects of different variables reported in studies of vitamin E supplementation in transition period of cows

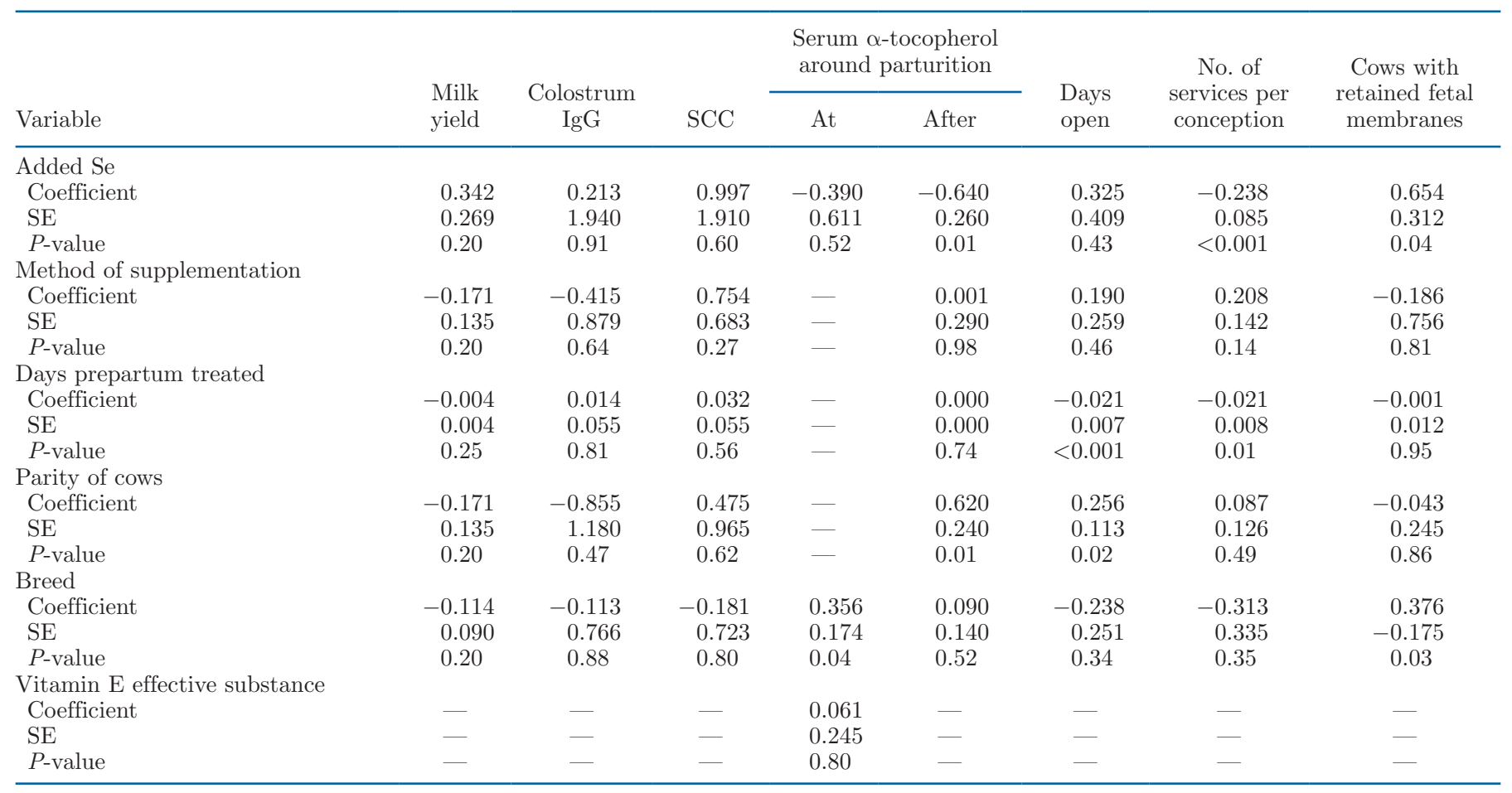


vitamin $\mathrm{E}$ on transition cows, this was not fully analyzed because of incomplete reporting of experimental details in many studies, which resulted in the exclusion of some experiments with important outcomes. This has been discussed in more detail by Winder et al. (2019) as a crucial limitation of meta-analysis studies. Therefore, it is suggested that a global format of describing the details of the studies on vitamins is complied with in future research. This approach would enable the researcher to thoroughly draw out the net effect of the vitamin of interest in future meta-analyses.

\section{Milk, Colostrum, and Blood Variables}

The result of the current meta-analysis showing a tendency for higher MY is consistent with the unclear trend of the vitamin E supplementation on the milk production performance. For example, several studies (Bayril et al., 2015; Schäfers et al., 2017; Vasil' et al., 2017) reported increased MY in cows treated with vitamin E, whereas other studies did not report a beneficial effect of vitamin $\mathrm{E}$ administration on milk production at levels higher than current NRC (2001) recommendations (Bourne et al., 2008; Anwar et al., 2014; Vasil' et al., 2017). Positive effects of vitamin E supplementation can be explained by the fact that prepartum vitamin $\mathrm{E}$ supplementation may increase DMI through increased glucose availability and levels, leading to increasing nutrient availability for milk synthesis (Chandra et al., 2013). It has been well demonstrated that prepartum DMI is positively correlated with postpartum DMI $(\mathrm{r}=0.53$, Grummer, 1995). Therefore, vitamin $\mathrm{E}$ is expected to indirectly increase postpartum DMI. Yet, highly significant heterogeneity pinpoints the involvement of many other variables in MY response of cows to vitamin E supplementation. Nevertheless, the dose response was linear, suggesting that within the range of vitamin E supplementation (175-2,327 IU/ head per day) in studies reporting MY in our database, higher dosages of vitamin $\mathrm{E}$ had a greater effect on MY. Moreover, the average increase in MY of $1 \mathrm{~kg} / \mathrm{d}$ likely justifies the cost of vitamin $\mathrm{E}$ application in every supplementation method.

It is generally accepted that inadequate intake of vitamin E predisposes the mammary gland to infections and results in elevated SCC. Because reducing SCC is associated with reduced risk of subclinical or clinical mastitis, nutritional practices are critical to lower the SCC, particularly in fresh cows (Kehrli and Shuster, 1994). The reducing effect on SCC of vitamin E is attributed to the enhanced levels of protection it provides against free radicals in alveolar cell membranes (Godden, 2008). Politis (2012) investigated the relationship between vitamin E supplementation and SCC using data from large-scale farm surveys and concluded that supplementation of 3,000 IU/d of vitamin E decreases SCC. However, this study did not observe any effect of vitamin E on SCC, which could be explained by the duration of supplementation, serum $\alpha$-tocopherol at dry-off, whether Se is co-supplemented, and the form and method of vitamin E supplemented.

Colostrum IgG concentration was not affected by prepartal vitamin $\mathrm{E}$ administration or its level. Similarly, Bass (1999) found that colostrum IgG was not different in vitamin E-treated and control cows. In contrast, Moeini et al. (2011) and Lacetera et al. (1996) reported significantly higher colostral IgG of cows injected with vitamin $\mathrm{E}$ prepartum. The placenta in cattle precludes transfer of immunoglobulins, and newborn calves rely on colostrum for the transfer of passive immunity (Kafilzadeh et al., 2014). Alveolar epithelial cells transport IgG from intracellular fluid into the mammary gland luminal space through endocytosis; the latter is downregulated by increased prolactin concentration as the pregnancy approaches the term (Godden, 2008). As vitamin $\mathrm{E}$ is involved in protecting the cell membrane from oxidative damage and maintains membrane integrity (Russell, 2000), increasing vitamin E supplementation might support enrichment of colostrum with immunoglobulins. The nonsignificant heterogeneity suggests that, irrespective of many factors that considered in the meta-regression, vitamin E supplementation is less likely to increase IgG concentration of colostrum. In the few studies in which $\operatorname{IgG}$ secretion positively responded to vitamin $\mathrm{E}$ administration, the yield, rather than concentration, of colostrum was improved. Instead, IgM and IgA concentrations were reported to increase in colostrum, indicating that vitamin E locally stimulated synthesis of immunoglobulins in the mammary gland (Lacetera et al., 1996).

It is important to note that the normal concentration of vitamin $\mathrm{E}$ in serum is reduced by $47 \%$ around parturition. The reasons are that vitamin $\mathrm{E}$ is utilized for secretion in colostrum, there is an increased requirement for antioxidative defense around parturition (Kafilzadeh et al., 2014), and there is a concurrent decrease in blood lipoproteins carrying vitamin E (Bass, 1999). It is known that the circulating concentration of $\alpha$-tocopherol $(2-4 \mu \mathrm{g} / \mathrm{mL})$ is highly correlated with the intake of vitamin $\mathrm{E}$ (Weiss, 1998), and this should encourage oral or parenteral administration to maintain blood vitamin $\mathrm{E}$ concentration of transition cows. This was confirmed in the current meta-analysis: prepartal vitamin $\mathrm{E}$ administration enhanced blood concentration of vitamin $\mathrm{E}$ at parturition. Also, the dose-response analysis showed that this effect was linear. However, pre- and postpartum dose responses 
were not significant for serum vitamin E concentration. It has been demonstrated that the dramatic change in vitamin $\mathrm{E}$ status at parturition is transient, ending shortly after parturition (Herdt and Smith, 1996). That pre- and postpartum vitamin $\mathrm{E}$ concentrations in the blood did not respond to supplementation might be because intestinal uptake of vitamin $\mathrm{E}$ diminishes as supplementation dose is increased (Baldi, 2005).

\section{Reproductive Traits}

Free radicals impair reproductive functions such as production of steroids and prostaglandins, quality spermatogenesis, and embryonic development (Aréchiga et al., 1994). There is a large variation in the results of studies that investigated the effect of vitamin $\mathrm{E}$ on reproductive performance, at least part of which attributable to differences in dosage and frequency of administration in prepartal cows. For instance, a high level of vitamin $\mathrm{E}$ did not reduce CFP in one study, but it reduced DO (Aréchiga et al., 1994). Campbell and Miller (1998) also reported a significant reduction of days to first service and a tendency for decreased DO; however, the incidence of RFM did not decrease with vitamin E supplementation. Our meta-analysis showed a decreasing effect of vitamin $\mathrm{E}$ on DO and a tendency to decrease CFP. In addition, the results showed that cows with greater parities might be less responsive to reducing CFP by administration of vitamin E, as previously reported (Hidiroglou et al., 1987). Promisingly, meta-regression showed that the previously known synergy between vitamin $\mathrm{E}$ and $\mathrm{Se}$ is extendable to reproduction so that co-supplementation of these nutrients improved CFP. As CFP and DO are somewhat interrelated (Pontes et al., 2015), the linear response of DO to vitamin E might suggest that increased dosages of vitamin $\mathrm{E}$ or added Se may also affect CFP; however, only 11 studies reported CFP, which might have been an insufficient number to detect a significant effect of vitamin E dosage or Se.

Expulsion of fetal membranes indicates a successful parturition that may improve subsequent reproductive performance (Sattar et al., 2007; Bayril et al., 2015). The RFM allows pathogens to colonize and spread infections throughout the genital tract, thus delaying subsequent conception and increasing unwanted culls (Kim et al., 1997). It is expected, therefore, that treatment of cows with vitamin $\mathrm{E}$ and Se stimulates the immune system prepartum (Kafilzadeh et al., 2014) and hastens expulsion of fetal membranes (Baldi, 2005; Bourne et al., 2007). This improves neutrophil function and reduces pathogen load in the first $30 \mathrm{~d}$ of lactation, which in turn, may reduce DO and SPC (Brozos et al., 2009; Bayril et al., 2015). In this aspect, RFM is frequently considered a health parameter rather than a reproductive measure. Here, we showed that RFM is decreased with vitamin E supplementation to transition cows. A meta-analysis combining the results of trials on 2,500 cows showed that prepartal supplementation of vitamin E significantly reduces the risk of RFM (Bourne et al., 2007), which was expected because the database used in the current study and that of Bourne et al. (2007) had many references in common. Also, these results were consistent with a large farm-scale investigation proving the efficacy of vitamin $\mathrm{E}$ in reducing the risk of RFM (Bourne et al., 2008). Likewise, the inconsistent results on RFM reported in the trials in the database of Bourne et al. (2007) were confirmed by the significant heterogeneity observed in our results. Despite a wide range of factors originally considered, only a few were addressed in the literature; therefore, meta-regression failed to comprehensively account for all factors affecting the response of vitamin E. Nevertheless, the significant effect of breed and the nonsignificant effect of parity in our meta-regression were consistent with those obtained in the latter study. Holsteins had a lower incidence of RFM compared with other breeds that received vitamin E.

Factors that increase the risk of RFM and may therefore interfere with vitamin $\mathrm{E}$ in reducing RFM might be related to parity. In primiparous cows, the greater risk of dystocia, and in multiparous cows, the greater negative energy balance and impaired Ca hemostasis might be involved. Unfortunately, details of rations in the papers in our database were not suficent to allow us to establish a relationship between dietary specifications and vitamin E supplementation. However, based on the variables included in the meta-regression model, vitamin E should be provided to cows of all parities.

Unexpectedly, the positive coefficient of added Se in the regression model indicated that supplementation of Se increased the proportion of cows with RFM. However, this coefficient had a large standard error (0.31) that comprised almost $50 \%$ of the value of the coefficient, suggesting that this outcome should be regarded with caution. This finding is also in opposition to other studies that reported a synergistic effect between vitamin E and Se on RFM (Juárez et al., 2009; Bayril et al., 2015). As most studies have used a combination of Se and vitamin E in the treated group, discriminating the specific effect of each of these compounds requires further investigation.

\section{CONCLUSIONS}

Results of this meta-analysis and meta-regression showed that administration of vitamin E significantly increased its serum concentration around parturi- 
tion and decreased the odds of RFM. Also, vitamin E promoted shorter DO and reduced the number of SPC. Vitamin E supplementation tended to increase MY, as well. Of the factors included in the regression model, breed, parity, and Se concentration of the diet interacted with the effect of vitamin E. Despite the involvement of many interacting factors, results suggest a linear effect of vitamin E supplementation on milk production and reproduction. We conclude that up to 3,600 IU/d of vitamin E as an oral supplement during transition appears to improve milk production and the reproduction performance of cows, an effect that could be synergistically amplified by Se supplementation.

\section{ACKNOWLEDGMENTS}

The study was funded by University of Tehran, Iran, and the Veterinary University of Vienna, Austria. Both parties are acknowledged. The authors have not stated any conflicts of interest.

\section{REFERENCES}

Anwar, F., M. S. Akhtar, C. Lal, L. A. Lodhi, M. M. Ayaz, I. Ahmad, A. A. Farooq, and M. Akhtar. 2014. Effect of prepartum administration of selenium and vitamin $\mathrm{E}$ on subsequent postpartum performance in first calf Nili-Ravi buffalo heifers. J. Anim. Plant Sci. 24:5-8.

Aréchiga, C., O. Ortiz, and P. Hansen. 1994. Effect of prepartum injection of vitamin $\mathrm{E}$ and selenium on postpartum reproductive function of dairy cattle. Theriogenology 41:1251-1258. https://doi .org/10.1016/0093-691X(94)90482-X.

Baldi, A. 2005. Vitamin E in dairy cows. Livest. Prod. Sci. 98:117-122. https://doi.org/10.1016/j.livprodsci.2005.10.004.

Baldi, A., G. Savoini, L. Pinotti, E. Monfardini, F. Cheli, and V. D. Orto. 2000. Effects of vitamin E and different energy sources on vitamin $\mathrm{E}$ status, milk quality and reproduction in transition cows. J. Vet. Med. A Physiol. Pathol. Clin. Med. 47:599-608.

Bass, R. T., II. 1999. Effects of vitamin E supplementation in late gestation cattle and evaluation of vitamin $\mathrm{E}$, cholesterol, and phospholipid relationships in bovine serum and serum lipoproteins. PhD Thesis. Virginia Polytechnic Institute and State University, Blacksburg.

Bayril, T., A. S. Yildiz, F. Akdemir, C. Yalcin, M. Köse, and O. Yilmaz. 2015. The technical and financial effects of parenteral supplementation with selenium and vitamin E during late pregnancy and the early lactation period on the productivity of dairy cattle. Asian-Australas. J. Anim. Sci. 28:1133-1139. https://doi .org/10.5713/ajas.14.0960.

Begg, C. B., and M. Mazumdar. 1994. Operating characteristics of a rank correlation test for publication bias. Biometrics 50:1088 1101. https://doi.org/10.2307/2533446.

Borenstein, M., H. Cooper, L. Hedges, and J. Valentine. 2009. Effect sizes for continuous data. Pages 221-235 in The Handbook of Research Synthesis and Meta-Analysis 2. Russell Sage Foundation, New York, NY.

Bourne, N., R. Laven, D. Wathes, T. Martinez, and M. McGowan. 2007. A meta-analysis of the effects of vitamin E supplementation on the incidence of retained foetal membranes in dairy cows. Theriogenology 67:494-501. https://doi.org/10.1016/j.theriogenology .2006.08.015.

Bourne, N., D. C. Wathes, K. E. Lawrence, M. McGowan, and R. A. Laven. 2008. The effect of parenteral supplementation of vitamin
E with selenium on the health and productivity of dairy cattle in the UK. Vet. J. 177:381-387. https://doi.org/10.1016/j.tvjl.2007 .06 .006 .

Bouwstra, R. J., M. Nielen, J. R. Newbold, E. Jansen, H. F. Jelinek, and T. van Werven. 2010. Vitamin E supplementation during the dry period in dairy cattle. Part II: Oxidative stress following vitamin E supplementation may increase clinical mastitis incidence postpartum. J. Dairy Sci. 93:5696-5706.

Brozos, C. N., E. Kiossis, M. P. Georgiadis, S. Piperelis, and C. Boscos. 2009. The effect of chloride ammonium, vitamin $\mathrm{E}$ and Se supplementation throughout the dry period on the prevention of retained fetal membranes, reproductive performance and milk yield of dairy cows. Livest. Sci. 124:210-215. https://doi.org/10 .1016/j.livsci.2009.01.018.

Campbell, M. H., and J. K. Miller. 1998. Effect of supplemental dietary vitamin e and zinc on reproductive performance of dairy cows and heifers fed excess iron. J. Dairy Sci. 81:2693-2699. https: //doi.org/10.3168/jds.S0022-0302(98)75826-6.

Chandra, G., A. Aggarwal, M. Kumar, A. K. Singh, V. K. Sharma, and R. C. Upadhyay. 2014. Effect of additional vitamin E and zinc supplementation on immunological changes in peripartum Sahiwal cows. J. Anim. Physiol. Anim. Nutr. (Berl.) 98:1166-1175. https:/ /doi.org/10.1111/.jpn.12190.

Chandra, G., A. Aggarwal, A. K. Singh, M. Kumar, and R. C. Upadhyay. 2013. Effect of vitamin $\mathrm{E}$ and zinc supplementation on energy metabolites, lipid peroxidation, and milk production in peripartum Sahiwal cows. Asian-Australas. J. Anim. Sci. 26:1569-1576. https://doi.org/10.5713/ajas.2012.12682.

Crippa, A., and N. Orsini. 2016. Multivariate dose-response metaanalysis: The dosresmeta R package. J. Stat. Softw. 72 (Code Snippet 1):1-15. https://doi.org/10.18637/jss.v072.c01.

Egger, M., G. D. Smith, M. Schneider, and C. Minder. 1997. Bias in meta-analysis detected by a simple, graphical test. BMJ 315:629634. https://doi.org/10.1136/bmj.315.7109.629.

Godden, S. 2008. Colostrum management for dairy calves. Vet. Clin. North Am. Food Anim. Pract. 24:19-39. https://doi.org/10.1016/ j.cvfa.2007.10.005.

Grummer, R. R. 1995. Impact of changes in organic nutrient metabolism on feeding the transition dairy cow. J. Anim. Sci. 73:28202833. https://doi.org/10.2527/1995.7392820x.

Herdt, T. H., and J. C. Smith. 1996. Blood-lipid and lactation-stage factors affecting serum vitamin $\mathrm{E}$ concentrations and vitamin $\mathrm{E}$ cholesterol ratios in dairy cattle. J. Vet. Diagn. Invest. 8:228-232. https://doi.org/10.1177/104063879600800213.

Hidiroglou, M., A. J. McAllister, and C. J. Williams. 1987. Prepartum supplementation of selenium and vitamin $\mathrm{E}$ to dairy cows: Assessment of selenium status and reproductive performance. J. Dairy Sci. 70:1281-1288. https://doi.org/10.3168/jds.S0022 -0302(87)80142-X.

Juárez, L. A. R., C. F. A. Flores, S. M. Roura, O. O. González, C. G. Gutiérrez, and J. H. Cerón. 2009. Incidence of uterine pathologies and fertility of Holstein cows treated with selenium and vitamin $\mathrm{E}$ before and after parturition. Vet. Mex. 40:133-140.

Kafilzadeh, F., H. Kheirmanesh, H. K. Shabankareh, M. R. Targhibi, E. Maleki, M. Ebrahimi, and G. Y. Meng. 2014. Comparing the effect of oral supplementation of vitamin $\mathrm{E}$, injective vitamin $\mathrm{E}$ and Selenium or both during late pregnancy on production and reproductive performance and immune function of dairy cows and calves. ScientificWorldJournal 2014:165841. https://doi.org/10 $.1155 / 2014 / 165841$.

Kehrli, M. E. Jr., and D. E. Shuster. 1994. Factors affecting milk somatic cells and their role in health of the bovine mammary gland. J. Dairy Sci. 77:619-627. https://doi.org/10.3168/jds.S0022 -0302(94)76992-7.

Kim, H. S., J. M. Lee, S. B. Park, S. G. Jeong, J. K. Jung, and K. S. Im. 1997. Effect of vitamin $\mathrm{E}$ and selenium administration on the reproductive performance in dairy cows. Asian-Australas. J. Anim. Sci. 10:308-312. https://doi.org/10.5713/ajas.1997.308.

Lacetera, N., U. Bernabucci, B. Ronchi, and A. Nardone. 1996. Effects of selenium and vitamin E administration during a late stage of pregnancy on colostrum and milk production in dairy cows, and 
on passive immunity and growth of their offspring. Am. J. Vet. Res. 57:1776-1780.

Lindqvist, H., E. Nadeau, K. Persson Waller, S. K. Jensen, and B. Johansson. 2011. Effects of RRR- $\alpha$-tocopheryl acetate supplementation during the transition period on vitamin status in blood and milk of organic dairy cows during lactation. Livest. Sci. 142:155163. https://doi.org/10.1016/j.livsci.2011.07.009.

Moeini, M. M., A. Kiani, E. Mikaeili, and H. K. Shabankareh. 2011. Effect of prepartum supplementation of selenium and vitamin e on serum Se, IgG concentrations and colostrum of heifers and on hematology, passive immunity and Se status of their offspring. Biol. Trace Elem. Res. 144:529-537. https://doi.org/10.1007/s12011 -011-9148-0.

Morgante, M., D. Beghelli, M. Pauselli, P. Dall'Ara, M. Capuccella, and S. Ranucci. 1999. Effect of administration of vitamin $\mathrm{E}$ and selenium during the dry period on mammary health and milk cell counts in dairy ewes. J. Dairy Sci. 82:623-631. https://doi.org/10 .3168/jds.S0022-0302(99)75276-8.

Nasrollahi, S. M., M. Imani, and Q. Zebeli. 2015. A meta-analysis and meta-regression of the effect of forage particle size, level, source, and preservation method on feed intake, nutrient digestibility, and performance in dairy cows. J. Dairy Sci. 98:8926-8939. https://doi .org/10.3168/jds.2015-9681.

NRC. 2001. Nutrient Requirements of Dairy Cattle. 7th rev. ed. National Academies Press, Washington, DC.

Politis, I. 2012. Reevaluation of vitamin E supplementation of dairy cows: Bioavailability, animal health and milk quality. Animal 6:1427-1434. https://doi.org/10.1017/S1751731112000225.

Pontes, G. C. S., P. L. J. Monteiro Jr., A. B. Prata, M. M. Guardieiro, D. A. M. Pinto, G. O. Fernandes, M. C. Wiltbank, J. E. P. Santos, and R. Sartori. 2015. Effect of injectable vitamin E on incidence of retained fetal membranes and reproductive performance of dairy cows. J. Dairy Sci. 98:2437-2449. https://doi.org/10.3168/jds.2014 -8886 .

R Core Team. 2014. 3.5.0 ed. R Foundation for Statistical Computing, Vienna, Austria.

Rosenthal, R. 1979. The file drawer problem and tolerance for null results. Psychol. Bull. 86:638-641. https://doi.org/10.1037/0033 $-2909.86 .3 .638$.

Russell, L. 2000. Vitamins in Animal and Human Nutrition. Iowa State University Press, Ames.

Sattar, A., R. Mirza, and S. Hussain. 2007. Effect of prepartum treatment of vitamin e-selenium on postpartum reproductive and productive performance of exotic cows and their calves under subtropical conditions. Pak. Vet. J. 27:105.
Schäfers, S., D. von Soosten, U. Meyer, C. Drong, J. Frahm, J. Kluess, C. Raschka, J. Rehage, A. Tröscher, W. Pelletier, and S. Dänicke. 2017. Influence of conjugated linoleic acid and vitamin E on performance, energy metabolism, and change of fat depot mass in transitional dairy cows. J. Dairy Sci. 100:3193-3208. https://doi .org/10.3168/jds.2016-11882.

Schäfers, S., D. von Soosten, U. Meyer, C. Drong, J. Frahm, A. Tröscher, W. Pelletier, H. Sauerwein, and S. Dänicke. 2018. Influence of conjugated linoleic acids and vitamin $\mathrm{E}$ on biochemical, hematological, and immunological variables of dairy cows during the transition period. J. Dairy Sci. 101:1585-1600. https://doi.org/10 $.3168 /$ jds.2017-13071.

St-Pierre, N. 2001. Invited review: Integrating quantitative findings from multiple studies using mixed model methodology. J. Dairy Sci. 84:741-755.

Torsein, M., A. Lindberg, C. Svensson, S. K. Jensen, C. Berg, and K. P. Waller. 2018. $\alpha$-tocopherol and $\beta$-carotene concentrations in feed, colostrum, cow and calf serum in Swedish dairy herds with high or low calf mortality. Acta Vet. Scand. 60:7. https://doi.org/ 10.1186/s13028-018-0361-0.

Vasil', M., F. Zigo, J. Elečko, M. Zigová, and Z. Farkašová. 2017. Effect of peroral supplementation with selenium and vitamin E during late pregnancy on udder health and milk quality in dairy cows. Slovak J. Food Sci. 11:535-538. https://doi.org/10.5219/766.

Weiss, W. P. 1998. Requirements of fat-soluble vitamins for dairy cows: A review. J. Dairy Sci. 81:2493-2501. https://doi.org/10 .3168/jds.S0022-0302(98)70141-9.

Winder, C. B., K. J. Churchill, J. M. Sargeant, S. J. LeBlanc, A. M. O'Connor, and D. L. Renaud. 2019. Invited review: Completeness of reporting of experiments: REFLECTing on a year of animal trials in the Journal of Dairy Science. J. Dairy Sci. 102:4759-4771. https://doi.org/10.3168/jds.2018-15797.

\section{ORCIDS}

MohammadHossein Moghimi-Kandelousi () https://orcid.org/0000 -0003-3575-362X

Ali A. Alamouti $\odot$ https://orcid.org/0000-0003-2867-9521

Mahdi Imani () https://orcid.org/0000-0002-3363-9279

Qendrim Zebeli @ https://orcid.org/0000-0001-5188-9004 